\title{
Polysemy and word meaning: an account of lexical meaning for different kinds of content words
}

\begin{abstract}
There is an ongoing debate about the meaning of lexical words, i.e., words that contribute with content to the meaning of sentences. This debate has coincided with a renewal in the study of polysemy, which has taken place in the psycholinguistics camp mainly. There is already a fruitful interbreeding between two lines of research: the theoretical study of lexical word meaning, on the one hand, and the models of polysemy psycholinguists present, on the other. In this paper I aim at deepening on this ongoing interbreeding, examine what is said about polysemy, particularly in the psycholinguistics literature, and then show how what we seem to know about the representation and storage of polysemous senses affects the models that we have about lexical word meaning.
\end{abstract}

\section{Introduction}

There is an ongoing debate about the meaning of lexical words, which, as a first approximation, can be characterized as words that contribute with content to the meaning of sentences. The distinction between functional and lexical words is notoriously difficult to make, but we can take it that, typically, lexical words are used to describe and categorize the world, whereas the role of functional words is more structural and language-internal. For the most part, linguistics has tended to treat lexical words in general terms only. However, this is not true anymore, as semanticists, pragmaticians, as well as psycholinguists have been paying more and more attention to the role that lexical words play in the construction of propositional meanings.

It has been observed that lexical words do not always contribute with the same conceptual meaning to propositional constructions. In some cases, this is because the word is overtly context sensitive. For instance, an adjective such as tall will express a different conceptual meaning when the standard of tallness is placed at one point of the scale of height than when it is placed at another point. But in many other cases, words are not overtly context sensitive, and yet they fail to express the same conceptual meaning in all occasions. For instance, the word mouth can denote the whole mouth, its outside part, a part of its inside part, its whole inside part, an aperture (such as in the mouth of the cave), the part of the river that opens into an ocean (river mouth), a whole person (I have two mouths to feed), a person who speaks too much (big mouth), etc.

The study of lexical word meaning has coincided with a renewal in the study of polysemy, which has taken place in the psycholinguistics camp mainly. There is already a fruitful interbreeding between two lines of research: the theoretical study of lexical word meaning and the models of polysemy psycholinguists present. In this paper, I deepen on this ongoing interbreeding, examine what is said about polysemy in the psycholinguistics literature, and then show how what we seem to know about the 
representation and storage of polysemous senses affects the models we have about lexical word meaning.

The paper is structured as follows: in Section 1, I describe three models of lexical word meaning, which are echoed by three similar models of polysemy representation. In Section 2, I distinguish different kinds of polysemy. Then, Section 3 shows that none of the models from Section 1 can fully account for the phenomena distinguished in Section 2 , and consequently argues against monolithic accounts of word meaning and polysemy representation. Section 4 examines the possibility that different classes of lexical words have different types of meanings, and deals with a problem that arises in connection with what has been discussed in the preceding sections.

\section{Models of polysemy and models of lexical word meaning}

\section{Word Meaning}

It is possible to distinguish three models of lexical word meaning, i.e. of what kind of meaning lexical words have. It is customary to differentiate between the standing meaning of a word and its occurrent meaning. The standing meaning of a word is the meaning the word has as a type, whereas the notion of occurrent meaning applies to particular tokens of that word-type. In the case of indexical terms, the standing meaning is taken to be the rule of application or character, while the occurrent meaning is the reference or denotation of a particular use of the indexical. In the case of lexical words, the distinction makes sense only if it is assumed that word-types have a meaning, over and above what they express in the context of an utterance. Meaning-eliminativists deny that word-types have any meaning at all. However, most authors take it that word-types have some kind of meaning, and that it thus makes sense to speak about the standing meaning of a lexical word. The main three general proposals are:

A. Literalism: each word-type has a literal, denotational, meaning. The rest of meanings it can have relates to linguistic rules, coercion, or pragmatic factors.

B. Underspecification (thin) account: the standing meaning of a word is underspecified with respect to its occurrent meaning.

C. Overspecification (rich) account: the occurrent meaning of a word is just a part (or a selection) of the total standing meaning of the word.

Here, labels can be misleading. Literalism follows the assumption that, among the various conceptual meanings a word can take, there is a privileged one, the rest being derivations of it. However, literalism can come in various guises, and the border between literalism and overspecification is not clear-cut. For instance, an overspecification approach such as the one defended in Zwarts (2004) and Hogeweg (2012), where the default meaning of a word is its most informational one, could count as literalist. Zwarts (2004), for instance, holds that the meaning of round includes the features COMPLETENESS, CONSTANCY, INVERSION, ORTHOGONALITY, and DETOUR. Round can express notions that have less features, i.e., that are thinner, but these are 
departures from the meaning of the word-type that, presumably, are obtained by suppressing some of the features that constitute the meaning of round. Also, an account of the meaning of polysemous nouns such as book that states that book has the meaning TEXT•TOME (more on this below), can be counted as literalist, since it can be said that TEXT•TOME is the literal meaning of book, and that the aspect TEXT (as in I enjoyed the book) and the aspect TOME (as in the book is heavy) are occurrent meanings derived from book's literal meaning. In order to distinguish literalism from overspecification, I will understand literalism as committed to the further hypothesis that the alleged nonliteral meanings are not obtained by a process of selection (in other words, the rest of the meanings are strictly derivations from the literal meaning).

An example of the literalist approaches that I have in mind is "classical” Relevance Theory (Sperber \& Wilson, 1985/96, 1998). According to this version of Relevance Theory, lexical words encode atomic concepts, although they rarely express them. Rather, words typically express ad hoc concepts, which are computed on the basis of the encyclopedic information associated with the concept that the word encodes as well as contextual factors. Thus, the word flat encodes the concept FLAT, but expresses the ad hoc concept FLAT* in the Tour de France this year is mainly flat. A very different literalist view could explain the variations in the concept that a word expresses in terms of coercion (see Asher, 2015 on flat) ${ }^{1}$. Coercion is essentially a mechanism by which hearers repair a type mismatch in the process of composition. A prototypical example of coercion is an utterance of

(1) Mary began the book.

Begin is an aspectual verb that requires an event as an argument. However, we find a non-eventive NP in its place. The idea then is that the hearer repairs this mismatch by coercing the NP into the eventive argument that the verb requires, obtaining the interpretation "Mary began reading the book". If we want to appeal to coercion in order to explain all variations in the concept that a word expresses, we need to assume that words have a literal meaning that undergoes coercion. For instance, if we want to explain that bottle in I drank the whole bottle refers to the content of the bottle as a result of coercion, we need to assume that the word-type bottle literally refers to the container.

The underspecification hypothesis about word meaning states that the standing meaning of a word is underspecified vis a vis its various occurrent meanings. The standing meaning is more abstract and general than the concepts we express when we use the word. Defenders of this view hold that the semantic values corresponding to word-types may have the "wrong format” (Recanati, 2004, Carston, 2012) to produce propositional contents. This, in most cases, amounts to saying either that there is a proprietary

\footnotetext{
${ }^{1}$ The more general view of Asher (2011) is more accurately classified as a mixed account: it is a literalist account for coercions and meaning shifts, but an over-specification (dot-object-ist) account as far as 'inherent polysemy' is concerned. Note, incidentally, that the different theoretical approaches discussed here were developed to handle different phenomena, not necessarily as general approaches to lexical semantics.
} 
semantic ontology, i.e. that there is a distinctive realm of meanings, a realm apart from the realm of contents, or that lexical word meanings, although conceptual in nature, are too schematic to enter into propositional contents.

Underspecification approaches are lately gaining in popularity. Chomsky's writings against truth-conditional, denotational, semantics have been clearly influential in this respect (e.g., Chomsky, 2000, Yalcin, 2014, Pietroski, forth.). However, Chomsky has not been the sole influence by any means. The contextualist movement in pragmatics has had a profound impact as well. For instance, Charles Travis' influential attack on truth-conditional semantics has many points in common with Chomsky's, both in terms of the kind of problematic examples he uses and in terms of the general lesson he seems to draw from these examples (Travis, 2008). Carston's (2002) and Recanati's (2004) brand of contextualism, on the other hand, has targeted the idea that lexical word meanings could be concepts (i.e. mental particulars) and that sentences could encode truth-evaluable compositions of concepts (i.e., psychologically real thoughts). However, underspecification hypotheses can be found elsewhere, both in work dating from the late eighties (Bierwisch and Schreuder, 1992) as well as in recent work in Cognitive Linguistics (Evans, 2009). Common to all of these different views is the idea that occurrent meanings of lexical words are always enrichments of their standing, schematic meanings.

The overspecification (rich) hypothesis is characterized by the tenet that occurrent conceptual meanings of words are selections, or parts, of their standing meanings. That is, the standing meaning of a word is taken to be a rich conceptual structure that typically exceeds what is being expressed when we use the word in a context. Overspecification accounts can be divided in two kinds. Overspecification holds that what is expressed by a word-token is a part, or a subset, of the conceptual meaning of the word. Now, this part can be proper or improper. If the part is proper, it follows that the occurrent meaning of a certain word will never be identical to its standing meaning. If the part is improper, then some uses of the word may express its standing meaning. This is the version of the rich meanings hypothesis that can be regarded as a version of literalism (see above). Both the "dot objects” account of polysemous terms such as book and Zwart's (2004) and Hogeweg's (2012) application of Optimality Theory to lexical semantics are exemplifications of this version of the rich meanings hypothesis.

The "dot objects" account of some polysemous terms traces back to Pustejovsky (1995). There, Pustejovsky proposed to explain a particular kind of polysemy, labeled 'inherent polysemy' (see below), by resorting to a new kind of type, which would be the result of merging two different types into a compound. Thus, the type of lunch in lunch was delicious but took forever is said to be the type event•food. The components of the compound are called 'aspects.'

However, Pustejovsky (1995) famously introduced another kind of version of the rich meaning/overspecification hypothesis (see also Moravcsik, 1975). In order to explain how coercion and other kinds of co-composition effects take place, he postulated that 
some words have informationally rich lexical entries that take the form of a qualia structure. According to Pustejovsky (1995), lexical meaning involves a structure consisting of four levels of representation: 'argument structure', 'event structure', 'qualia structure', and 'lexical inheritance structure.' The qualia structure of a lexical item (usually exemplified by nouns) is the hallmark of Pustejosky's theory and includes information about how the object came into being (agentive role), what kind of object it is (formal role), what it is for (telic role), and what it is constituted or made of (constitutive role). In some accounts inspired by the Pustejovskyan proposal, qualia structures are thought to provide 'aspects' or 'facets' (that is, different ways of seeing a given entity) ${ }^{2}$, which are also the senses that enter into truth-conditional compositions (Cruse, 2004; Frisson, 2009; Paradis, 2004), an idea reminiscent of Langacker's (1984) notion of 'active zones.' This liberal reading of Pustejovsky's qualia structures exemplifies the "proper parts" version of rich meanings, since words never express a complete qualia structure, but only a part of it.

As will be seen, many psycholinguists believe that the semantics of a word-type can be a structure that offers different possibilities of meaning. This, again, is a proper parts version of the overspecification hypothesis. Rayo's (2013) proposal that word-types give access to a "grab bag" constituted by exemplars, prototypes, theories, and other structures, is yet another possible exemplification of this version of the hypothesis, as is Vicente and Martínez Manrique’s (2016) view that words give access to a rich conceptual structure.

\section{Polysemy}

The three views about word meaning outlined above, correspond to three similar accounts on polysemy, in particular, on how polysemy is represented and stored. Polysemy is the well-known observation that a word has various different but related meanings. In this, it is contrasted with monosemy, on the one hand, and homonymy, on the other. While a monosemous form has only one meaning, a homonymous form is associated with two or several unrelated meanings (e.g., coach; 'bus', 'sports instructor'), and is standardly viewed as involving different lexemes (e.g., $\mathrm{COACH}_{1}$, $\left.\mathrm{COACH}_{2}\right)$.

There is a growing interest in polysemy, especially in the psycholinguistics camp, which focuses on differences in access, storage and representation of polysemous senses vis a vis homomymous meanings (the different related meanings of polysemous expressions are standardly called 'senses': Frisson, 2009). However, polysemy is also studied from different perspectives, such as computational linguistics (Pustejovsky, 1995, Copestake and Briscoe, 1995, Asher, 2011), pragmatics (Falkum, 2011), psychology (Srinivasan and Rabagliatti, 2015), cognitive linguistics (Brugman, 1988, Evans, 2015), theoretical semantics (Jackendoff, 1992), and lexicography (Kilgarriff, 1992, Hank, 2013). As said above, it is possible to group the different views that have

\footnotetext{
${ }^{2}$ Note that this is a liberal use of Pustejovsky's technical notion of aspect, which can give rise to occasional misunderstandings.
} 
been defended concerning how senses are represented and stored into three main theories:

A'. Literalism: each polysemous term has a literal, denotational, meaning. The rest of senses it has are generated on the basis of linguistic rules, coercion, or pragmatic inferences.

B'. Underspecification (core meaning) account: the meaning of a polysemous term is an underspecified, abstract, and summary representation that encompasses and gives access to its different senses.

C'. Overspecification (rich) account: the meaning of a polysemous term includes all its different senses, which are stored in a single representation. Senses are selections of the total meaning of the word.

I will understand literalism with respect to polysemy in the same way as above: basically, a position that can also be described as an instance of overspecification does not count as literalist. Literalism is partly endorsed by Asher (2011, 2015), where, as mentioned, he tries to explain a good number of meaning variations in terms of coercion, as well as by representatives of Relevance Theory such as Falkum (2011, 2015), and Copestake and Briscoe's account of some regular polysemies (1992) (see Falkum and Vicente, 2015, for a review).

Recent psycholinguistics tends to favor underspecification and overspecification approaches. What distinguishes one from the other is the question of whether access to the different senses of a word is direct or goes through an intermediate station called “common core” (Klepousniotou, et al. 2008; see also Brocher et al., 2016). The common core of, e.g. the different senses of the verb cut could be "change of state in which an entity which exemplifies some kind of connectedness undergoes a process of controlled disconnection" (Spalek, 2015). Whenever a reader finds the word cut in a text, she activates that common core representation. It may be that she is not required to home in on a more specific sense, and thus this is the only representation that is accessed, even if more specific interpretations are also activated (Frisson, 2009). However, the reader may need to home in on a specific sense of the word. In this case, she would easily retrieve the specific sense from the constellation of senses the underspecific representation gives access to.

In this respect, polysemy resolution differs from homonymy resolution, where (a) readers need to home in on a specific meaning as soon as they encounter the homonym, (b) there is a clear bias towards the dominant meaning, and (c) different meanings compete against each other, so that the meaning that is not selected quickly decays. According to Frisson (2009, 2015), Klepousniotou et al. (2012), MacGregor et al. (2015), and others, in polysemy resolution we do not see a strong bias for the most frequent, or dominant, sense. Indeed, senses prime each other no matter which sense is more frequent, and their common activation survives for at least $750 \mathrm{~ms}$ (MacGregor et al., 2015). These observations, together with the further observation that words with 
multiple senses are recognized faster (in lexical decision tasks) than words with less senses and, especially, than homonyms (Azuma and van Orden, 1997), suggests that the representation and storage of polysemous senses is very different from the representation and storage of homonym meanings (see also similar results concerning production reported in $\mathrm{Li}$ and Slevc, 2016). As it is customary to think that homonymous meanings are stored in different lexical representations, the model of polysemy representation and storage has to be different from the sense enumeration lexicon some advocated in the past (Katz, 1972) ${ }^{3}$.

Psycholinguists, however, cannot decide which one of the two possible competitors (underspecification and overspecification) best fits their data. Thus, Frisson (2009; 122) states:

"At the moment, it seems impossible to distinguish between all these different views on the basis of experimental results. However, what all these views seem to have in common, whether one considers the lexical representation to be semantically rich or not ... is the idea that what is initially accessed is not a full-fledged, specific interpretation of a word".

Similarly, MacGregor et al. (2015; 137) hold:

"The current results do not directly address the nature of polysemous representations, but they are compatible with the possibility that polysemes exist as a basic or common, core representation, which could be seen as underspecified... An alternative to an underspecified polysemous representation is one that is semantically rich comprising all relevant information associated with a particular word form. Over time as more meanings are acquired the representation becomes richer”.

However, the underspecification and the overspecification approaches are theoretically very different. The former, but not the latter, is committed to there being a summary representation or common core that encompasses all the different senses, a representation that a reader/hearer can retrieve if she is not particularly pressed to go for a more specific sense. As will be seen below, not all kinds of polysemy fit within a model with this commitment on board.

As mentioned above, the most influential overspecification approach to polysemy is Pustejovsky's (1995). The account based on the notion of "dot objet" seems to be able to explain a great number of facts concerning "inherent” polysemy (see below), while the liberal reading of his qualia theory accounts for other kinds of sense alternations (Cruse, 2004, Paradis, 2004, Vicente, 2012, 2015), where different aspects, or facets, of the total conceptual meaning of the word are differentially highlighted.

\footnotetext{
${ }^{3}$ Not all psycholinguists are convinced. Some authors (e.g., Klein and Murphy, 2001, Foraker and Murphy, 2012) advocate a SEL model. However, there seems to be emerging a consensus according to which the SEL model could be a good model only for distantly related senses (e.g. shredded paper vs liberal paper).
} 
In what follows, I will assume that a theory of word meaning needs to be able to account for polysemy, that is, that a good account of word meaning is also a good account of polysemy. If we have a theory of word meaning that cannot explain some facts about the phenomenon we call polysemy, then there is something wrong with that theory. The next two sections are devoted to explaining that none of the accounts of polysemy (A'-C') listed above can explain the whole range of observations we currently know about polysemy, the implication being that none of the accounts of word meaning (A-C) are good (unrestricted) theories of word meaning. I will argue that, prima facie, we should adopt a "mongrel" view according to which different classes of words have different kinds of meanings (rich vs. thin). Then, in Section 4, I will raise a problem for this account.

\section{Interesting kinds of polysemy}

In this section, I will present some "facts" about polysemy concerning processing, representation and storage, as well as concerning linguistic tests like co-predication and anaphoric binding. These facts will be presented and discussed in relation to a prototaxonomy of polysemy patterns. Most research on polysemy has either focused on just one kind of polysemy or failed short of distinguishing one kind from another. However, it is important to differentiate kinds in the study of polysemy because, as it will be seen, differences are substantial and revealing. The taxonomy I offer is motivated by the concerns about word meaning that motivate this paper. I think that, with these concerns in mind, it is possible to distinguish three broad kinds of polysemy: inherent or logical polysemy, merely regular polysemy, and metaphor-based polysemy.

\section{Inherent or logical polysemy}

The label 'inherent polysemy' was introduced by Pustejovsky (1995) to refer to a special kind of regular polysemy. Apresjan (1974: 16) described the polysemy of a word $A$ in a given language with the meanings $a_{i}$ and $a_{j}$ as being regular if "there exists at least one other word $B$ with the meanings $b_{i}$ and $b_{j}$, which are semantically distinguished from each other in exactly the same way as $a_{i}$ and $a_{j}(\ldots)$.” The characteristic feature of inherent polysemy, according to Pustejovsky, is that the different senses of the word in question are of contradictory types. For instance, book in (3a) is of the type info while in (3b) it is of the type physobj. The type of lunch in (4a) is food, and in (4b) it is event (Pustejovsky, 2005):

(3a) Mary has written an excellent book.

(3b) John sold his books to Mary.

(4a) I have my lunch in the backpack.

(4b) Lunch was really long today. 
Pustejovsky (1995) postulates the existence of a special complex type, dot-object, to account for inherent polysemy. Thus, book is not of the type info or physobj, but of the type info•physobj. The types info and physobj are the types of the aspects that constitute the dot object (which can be described as TEXT and TOME, Cruse, 2004). Aspects can be highlighted differentially, as in (3a, b) and (4a, b), respectively. But a peculiarity of dot objects is that they pass co-predication and anaphoric binding tests. Thus, in (5) the book is said to have simultaneously a property that only informational objects can have and a property that only physical objects can have. A similar thing, mutatis mutandis, occurs in (6) with respect to lunch.

(5) That heavy book is real fun.

(6) Lunch was delicious but took forever.

Asher (2011) calls 'logical polysemy' regular polysemy that passes co-predication and anaphoric binding tests, and postulates a "dot-objectual” meaning whenever a word exhibits "logical polysemy.” While co-predication tests are not completely reliable (Dölling, forth), they seem to reveal that we can successfully refer to a whole dotobject, or, putting it in other words, that we can think of entities that belong to different, complementary kinds, as coherent, individual, entities. At the same time, we can also conceptualize these entities as involving two different entities, their aspects. Thus, one may think of a book as a physical object (tome) only, as an informational object (text) only, or as both at the same time. In principle, there is no limitation as to the number of aspects that constitute a dot object. In (7), for instance, Brazil refers to a land, an institution, and a people:

(7) Brazil is a large two-century-old Portuguese-speaking country (Arapinis and Vieu, 2015)

Frisson (2015) presents a study of how we process what he calls "book" polysemies (e.g., book, manuscript, notice, journal, etc.), with results that can be plausibly extended to at least all kinds of inherent polysemies. The study consists in two experiments: a sensicality task and an eye-movement experiment. In the sensicality task, subjects were presented with a prime NP in which the adjective focused on either the tome (e.g., bound book) or the text (e.g., scary book) sense. Then, they were asked to make a sensicality judgement about a target NP in which the adjective focused on either the consistent (e.g., [well-plotted book], scary BOOK), or the inconsistent (e.g., [bound book], scary BOOK] sense. The results showed a clear consistency effect, with increased processing times in the inconsistent condition compared to the consistent condition, but no effect of either sense dominance or direction of sense switch (tome to text or text to tome) in the inconsistent condition. In the subsequent eye movement study, there were three conditions: The neutral conditions aimed at testing how quickly a specific sense is assigned to a polysemous word without prior contextual indication. The repeat conditions aimed at testing the effect of sense repetition on ease of processing. Finally, the switch conditions tested whether switching from one sense to a competing sense involves extra processing costs. 
In the neutral conditions, subjects did not have more difficulty disambiguating towards the subordinate than the dominant sense of the polysemous noun. In the repeat conditions, subjects spent more time reading the polysemous noun than in the neutral condition, but the time to select a particular sense was not affected by sense frequency. In the switch conditions, processing was more difficult than in the neutral context, and switching from a subordinate to a dominant sense induced greater costs than vice versa. These results suggest that "book" polysemies are processed very differently from both homonyms and other kinds of polysemies where senses are related but distant (Klein and Murphy, 2001, Foraker and Murphy, 2012). They also strongly suggest that the different senses of inherent polysemous expressions are stored together with a single representation (vis a vis homonymous meanings, stored in different representations). As will be seen, this kind of results is not specific to inherent polysemies. Thus, inherent polysemies can be said to conform a linguistic kind but not a psycholinguistic kind.

\section{Merely regular polysemy}

In a good number of regular patterns of polysemy we see a close, metonymic, relationship between the different senses of a certain word. However, they are not cases of inherent polysemy, since, although they can occasionally pass the co-predication test (depending on the pattern), it seems that it makes little sense to account for them in terms of dot-objects (Pustejovsky, 2005). Firstly, we have a strong intuition that one of the senses is derived from the other, in particular by means of metonymy. Secondly, and more important, it does not look like the two senses refer to entities which can be seen as being fused into a single whole. Instances of this kind of merely regular polysemy are patterns such as animal/meat/fur (8a, b, c), count/mass ( 9 a, b), tree/wood (10a, b), or liquid/portion of liquid (11a, b).

(8a) That rabbit is fast,

(8b) We have rabbit for lunch,

(8c) He is wearing a rabbit coat.

(9a) He ate an apple,

(9b) There was apple all over the floor.

(10a) This region is full of oaks,

(10b) Oak is more expensive, but also more elegant.

(11a) She doesn’t drink alcohol, not even beer,

(11b) She is having a beer.

It is not clear, however, whether a polysemy pattern exemplifies inherent or merely regular polysemy. Though the senses in (12a-f) are related in a part-whole relation, it is not obvious that they do not form a dot object, or at least, that they cannot be regarded aspects of a total meaning of mouth that would include them all: 
(12a) Open your mouth (cavity)

(12b) He has a beautiful mouth (lips)

(12c) You cannot live without a mouth (whole thing, abstract)

(12d) Put that into your mouth (inside)

(12e) I have a pain not in my teeth, but in my mouth (palate)

(12f) Wonderful words came out of her mouth (speech organ).

Copestake and Briscoe (1995) propose to account for cases like (8-11) by means of rules such as universal grinder (which takes the meaning of a count noun and gives the meaning -substance- of a mass noun), or meat grinder (which goes from the animal sense to the food sense). Frisson and Frazier (2005) found some evidence for this account, although Klepousniotou et al. (2008) found that in the rabbit case each sense (animal and meat) primes the other, and that there are no dominance or frequency effects. Their study was also a sensicality task involving neutral, conflicting, and consistent contexts (see above). It turned out that, while for homonyms and "distant" polysemes there was between-meaning competition, in the rabbit cases, just like for book cases, it rather looked like both senses were stored together.

Pustejovsky (2005) recommends explaining the polysemies in (8-11) in terms of rules, and the container/content alternation in $(13 \mathrm{a}, \mathrm{b})$ as "explotation of the telic role":

(13a) Who is carrying the bottle?

(13b) I drank the whole bottle.

So it is possible that these regular polysemies are special, and even that some instances are better treated in terms of a "one representation" approach, while others involve going from one sense to the other either by means of a rule or by pragmatic inference (Falkum, forth.).

Apart from these typical instances of regular polysemies, there are other cases that have been scarcely studied, but that could be included in the present group. For instance, Machery and Seppälä (2011) present a number of statements, such as Tina Turner is a grandmother, where subjects tend to respond "in a sense, yes/ in a sense, no", and argue that grandmother is polysemous between a definition and a prototype sense. In a related study, Knobe et al. (2013), used words like scientist or friend to show that there are two different rules of application related to two different senses of these words. If asked whether some non-academic who is very inquisitive and methodical is a scientist, subjects also tend to respond "in a sense, yes/ in a sense, no". It seems that some words fall under regular patterns of sense alternation which could be described as definition/prototype (Machery and Seppälä, 2011), and concrete features/abstract ideal (Knobe et al., 2013). 
Metonymy is one of the major polysemy-generating mechanisms. The other major mechanism is metaphor. Whereas metonymy-based (either inherent or merely regular) polysemy affects mainly nouns, proper or common (as can be seen by looking at the above examples), metaphor-based polysemy affects all kinds of words, from nouns and prepositions to adjectives and verbs. Metaphor-based polysemy is typically irregular (in the Apresjan's sense) and rather idiosyncratic. The relationship between the different senses is one of similarity, and similarity is in a good part up to the eye of the beholder.

Whereas metonymy-based polysemies has attracted great attention from computational and formal semanticists, metaphor-based polysemy has been the focus of a good number of studies within the Cognitive Linguistics tradition, starting with Lakoff (1987) and Brugmann's (1988) work on the polysemy of over. The hypothesis that many cognitive linguists defend is that metaphor-based polysemies are structured in terms of meaning-chains which stem from a prototypical, usually embodied, meaning of a word, and extend in various ways. Brugmann listed as many as one hundred different senses of over.

This kind of polysemy does not pass co-predication or other tests, like conjunction reduction. Rather, concatenation of senses typically creates zeugma (Zwicky and Sadock, 1975), as in:

(14) Arthur and his driving license expired yesterday.

Some cognitive linguists seem to endorse a sense enumeration model concerning the storage of this kind of polysemy (Brugman, 1988), but recent psycholinguistic studies question this view. For instance, MacGregor et al. (2015) tested the polysemy of mouth as in mouth of a person, mouth of a river and mouth of a cave, and observed the same overall pattern of co-priming and facilitation effects observed in regular polysemy. While there are some differences between the two cases (regular vs metaphor-based polysemies) with respect to the speed of response in a lexical decision task (Keplousniotou and Baun, 2007), and, in general, in the time it takes for one sense to activate another (MacGregor et al., 2015), both cases seem to pattern together when the contrast class is homonymy. In particular, within $750 \mathrm{~ms}$ after prime offset, an incoherent meaning of a homonymous word has decayed, whereas an incoherent sense of a polysemous word is still activated. MacGregor et al. $(2015 ; 138)$ therefore conclude that, also in the case of metaphor-based polysemies, "sustained activation of both meanings of polysemous words supports an account of representation in which the multiple senses are stored together" and that "the different senses act collaboratively to strengthen the representation, which facilitates the maintenance even after a long delay".

Where they waver is about the way to interpret their results (see above): 
"The current results do not directly address the nature of polysemous representations, but they are compatible with the possibility that polysemes exist as a basic or common, core representation, which could be seen as underspecified... An alternative to an underspecified polysemous representation is one that is semantically rich comprising all relevant information associated with a particular word form. Over time as more meanings are acquired the representation becomes richer”.

\section{Where the models fail}

The aim of this section is to show that none of the models of polysemy representation (A'-C') presented above can account for all the three cases of polysemy distinguished in the previous section.

\section{Inherent polysemy cannot be accounted for by (A') and (B')}

Literalism (A') implies that there is some kind of hierarchy in the world of senses. One of them is the meaning of a word, and the rest is derived. In the case of metaphor-based polysemies, it is prima facie reasonable to assume that, e.g., the human organ meaning of mouth is its literal meaning, with the other senses being derived from it. However, there seems to be no reason to assume that the text (or the tome) sense of book is its literal meaning. Even if one sense is more frequent than the other (it seems that the text sense of book is more frequent than its tome sense, see Frisson, 2015), given that each activates the other on a regular basis, it is not credible to say that the most frequent sense is the literal meaning. Besides, the literalist hypothesis lacks an explanation as to why inherent polysemy allows for co-predication. There seems to be something really special about this kind of polysemy. What is it, according to a literalist?

The underspecification, thin, approach (2') does not have any account as to why these polysemous terms pass co-predication tests either. The theory states that the meaning of a polysemous term is some abstract or summary representation that encompasses the different senses the word has. This theory is intended to apply to all sorts of polysemy, or at least to the sorts of polysemy we have considered here. The question is why inherent polysemy, but not the others, pass co-predication tests. This is still to be explained.

However, the really damaging problem for the underspecification approach is that there is no summary or abstract representation that encompasses all the senses of an inherent polysemous expression. Klepousniotou et al. (2008: 1535) describe a core meaning as "a memory structure encompassing all semantic features that are common across multiple senses of a polysemous word (e.g., for the word 'rabbit', a core representation might include [+ANIMATE, +FARM ANIMAL, +EDIBLE, +MEAT].” However, as Foraker and Murphy (2012) reply, it is not the case that rabbit retains the four features described above in the sentences I saw a rabbit running and I am cooking rabbit. In the case of a running rabbit, the rabbit is not edible, and it is not meat. In the case of rabbit meat, the rabbit is not animate. In general, polysemous senses that belong to a regular pattern of polysemy do not share features that could build a core meaning, a summary 
representation, or an underspecific representation that covers all of them. In the particular case of inherent polysemies, there seems to be nothing in common between book-the-text and the book-the-tome, between Brazil-the-people, Brazil-the-institution, and Brazil-the-land, or between school-the-institution, school-the-process (School starts at 9), school-the-building, and school-the people (I have to talk to the school). The only representation that encompasses all of the different uses of book, Brazil, and school is one that lists them all.

The overspecification, or rich, hypothesis then emerges as the only plausible contender with respect to inherent polysemy. A model such as the dot-object approach seems to be able to explain co-predication (in fact, it was "designed" to do that). On the other hand, as we have seen, psycholinguists only seem to consider two hypotheses: an underspecific and an overspecific approach. In this case, the choice is clear. We have to hold that the polysemy of, e.g. school can only be explained if the meaning of school is a whole formed by aspects that can be selectively activated.

Merely regular polysemy is problematic for (B')

The case against literalism with respect to merely regular polysemy is not as clear as in the case of inherent polysemy. Whereas we lack intuitions about which of the two senses of book should be considered its literal meaning, we have intuitions about which sense of oak (tree or wood) or apple (count or mass) is the literal meaning of each of these words. Actually, rule-based approaches (Copestake and Briscoe, 1995) are aimed precisely at this kind of polysemies. And pragmatic (Falkum, 2010, forth.) and coercion (Asher, 2011, 2015) proposals have also been advanced. Finally, as noted above, the empirical results are not clear-cut. So, perhaps literalism is an option with respect to some cases (e.g., most instances falling under the mass-count alternation) and overspecification the best explanation of other cases (container-content and rabbit cases). The option that seems to be ruled out is underspecification, because, as has been mentioned before, there is no common core that encompasses the different senses of a merely regular polyseme.

\section{Overspecification fails at (C')}

The psycholinguistic evidence related to the lack of frequency effects and to co-priming constitutes evidence against literalism and sense enumeration, but, as it has been stressed, it does not distinguish between the under- and the over-specification hypotheses, according to psycholinguists. In the cases of merely regular and inherent polysemy we have appealed to the lack of a summary, abstract, representation that could cover the different senses in order to argue for an overspecification model. However, metaphor-based polysemies are very different from metonymy-based polysemies in this respect. Metonymic senses are closely related, but they, arguably, do not share (many) features. However, metaphors are based on similarity, which can be explained in terms of feature-sharing (cf. Brocher, et al., 2016). 
In metaphor-based polysemies there is also an intuitive pull towards a literalist hypothesis. After all, metaphors are constructed on the basis of a literal meaning. However, the question is whether, once metaphorical meanings have been constructed and conventionalized, we need to calculate them on the basis of these literal meanings. Metaphor-based polysemy has not been as thoroughly studied as metonymy-based polysemy, but, from what we know so far, we might conclude that there is no literal/metaphorical distinction at the level of processing, i.e. that there is not a representation of the literal meaning that we access first in order to find or construe a metaphorical sense (at least when that sense is conventionalized, i.e. when we are dealing with actual polysemes).

It is also noteworthy that, whereas metonymy generates a limited number of senses, metaphor is able to create hundreds of them (Brugman, 1988). Besides, it is difficult to decide how many senses there really are. For instance, cut surely has lots of senses (Elman, 2009), but it is not clear whether in cut the grass and cut the cake, cut expresses different senses, something that does not seem to happen in metonymy-based polysemy. Another difference between these two kinds of polysemy worth mentioning is that it is simply impossible to call the senses of a metaphor-based polyseme, aspects. The mouth of a river and the mouth of a cave are not aspects of a mouth. They are related to aspects of mouths, as bigmouth, mouth of Sauron, and mouth to mouth, are expressions related to aspects of mouths. Yet, they do not denote such aspects.

If we leave literalism at one side and we face the recurrent choice between the underand the over-specification models, this time we need to side with underspecification. Two reasons seem to be strong enough. First, in metaphor-based polysemy there can be a summary or abstract representation that applies to all the different senses (Brocher et al., 2016). Second, the number of senses is way too large to believe in a representation formed by all of them. The most plausible hypothesis in this case is that the summary, abstract, or core meaning representation plausibly consists of a number of features that form part of all the metaphorical senses. The activation of these features spreads to all the senses that include such features, which explains co-priming. The more features are shared, the more activation they receive.

If we move the focus to verbs, we can see that the underspecification hypothesis is actually quite convincing. Let me begin with the relative unboundedness nature of verb senses. If it is conceded that the senses in play in cut the grass and cut the cake are different (though clearly related), then it seems that the senses of cut can extend without any obvious limitation. This, of course, is not to say that cut can be made to mean anything whatsoever. The point is just that there seems to be no principled list of possible senses of cut. A plausible reason for this behavior of verbs is that the different senses of a verb relate to the internal arguments they take. It is now well-attested that alleged semantic features of verbs such as aspectuality (whether they denote states, activities, accomplishments, or achievements) and the possibility of certain argument alternations, are rather features of whole VPs (for aspectuality, Dowty, 1979; for 
argument alternations, Rappaport Hovav, 2014). It should not be surprising that what we take to be verb meanings are, actually, dependent on whole VPs.

For instance, depending on the internal argument it takes, cut may have different grammatical behavior. Thus, cut typically enters into the conative alternation (John cut the rope/ John cut at the rope), but not always: the bank cut at its interest rates does not sound correct (Falkum, 2011) ${ }^{4}$. Thus, it seems that the different senses of verbs are generated or retrieved (depending on the level of conventionalization) in composition, and in particular, that they partly depend on the internal argument verbs they take (see Spalek, 2015, for a development). The lexical meaning of cut can be very abstract, so that it covers both uses of cut in cut the grass and cut the interest rates. Spalek (2015), for instance, proposes that the lexical meaning of the Spanish verb cortar (roughly, but not exactly, equivalent to $c u t)^{5}$ encodes a change of state in which an entity which exemplifies some kind of connectedness undergoes a process of controlled disconnection ${ }^{6}$. This kind of abstract meaning could be the common core present in all uses of cortar, both in its more "literal" and in the more figurative uses (like cortar la circulación/stop the traffic). This common core would give access to more specific senses, which express what it means to cut a given entity or kind of entity.

Regardless of the story that is put forward about how we go from the underspecific meaning to specific senses (either via on-line co-composition or by directly accessing stored specific senses), it seems that the underspecification model fares much better than the overspecification account when it comes to explaining verb meaning variations. As such variations are typically similarity-based, it makes sense to consider that metaphor-based polysemies in general fit the underspecification approach better.

\section{Classes of words: different types of meanings}

It is tempting to think that different classes of words have different kinds of meaning. In particular, it seems that nouns that denote kinds or individuals have rich meanings, while most other nominals, as well as most verbs, prepositions, adverbs, and adjectives have thin meanings. If we use the polysemy "facts" to build our account of word meaning, this is the picture that seems to emerge. These facts show that only some nominals (mostly, kind terms and proper names) enter into regular patterns of polysemy, which is the one that suggests a rich meanings view.

The idea that prototypical nouns have a differentially richer meaning can be supported by other considerations. One such consideration appeals to the semantic behavior of

\footnotetext{
${ }^{4}$ Another example: 'break' typically admits the anticausative alternation ('Jonh broke the window'/'the window broke'), but not always: 'John broke the law' is ok., but 'the law broke' is not (see Spalek, 2015, Rapapport Hovav, 2014)

${ }^{5}$ The translation of 'cut the interest rates', for instance is not 'cortar los tipos de interés' but 'recortar los tipos de interés'.

${ }^{6}$ The proposal has problems, as when the cut is not controlled, as in 'the rope cut', or 'se cortó la cuerda' (Spanish). It is certainly difficult to find necessary conditions rather than prototypical conditions.
} 
verbs that has just been mentioned, according to which only VPs, but not verbs taken in isolation, have interesting semantic properties. One way of explaining how VPs get their meaning properties is to appeal to the interaction between the thin meaning of the verb and the rich meaning of its arguments. To use an example from Pustejovsky (1995), the difference between bake a cake (create) and bake a potato (warm up) is explained as the result of the interaction between the schematic meaning of bake and the lexical information provided by the nouns (cakes are artefacts; potatoes are natural kinds). Similarly, the fact that the intransitive the rope cut is acceptable (Rappaport Hovav, 2014 ${ }^{7}$ ) seems to depend on the rich meaning of rope, and the unacceptability of the law broke is explained by virtue of the rich meaning of law. In sum, when the arguments of a verb are kind terms, we witness what look like "modulations" of verb meanings that can affect their usual grammatical behavior.

Another argument that supports the view that kind terms and some proper nouns (particularly names of cities or of countries) ${ }^{8}$ may be semantically different to the rest of words draws on the nature of kind-concepts in general. As Carey (2009) puts it, kindconcepts are "inductively deep" (see also Millikan, 2000 on the difference between substances and classes). We draw lots of inferences based on our kind-concepts because they store lots of information. In contrast, concepts of properties or events are informationally “flat” (Millikan, 2000; see also Pritchard, 2017). Actually, it seems that common nouns in general behave like attractors of information or nodes of inference. Even very young children are prone to generalize and make inferences when the label they hear is a common noun, but are much more cautious when the words used are adjectives or form descriptions (Fennell \& Waxman, 2010). This is related to the essentialist stance: kind terms are assumed to denote categories with essences, categories which are the "joints" of nature. We store information about these categories because they are the ones that allow us to make inferences and generalizations. The point, thus, is that a kind term will typically give access to much more information, and will relate to a bigger/richer concept, than any other term.

\footnotetext{
${ }^{7}$ See (Rappaport Hovav and Levin, 2014):

a. ... the rope cut on the rock releasing Rod on down the mountain.

(http://www.avalanche-center.org/Incidents/1997-98/19980103a-Montana.php)

b. The sheath of the rope had cut on the edge of the overhang and slid down 2

feet. (www.rockclimbing.org/tripreports/elnino.htm)

c. The rope cut and the climber landed on his feet, stumbled backward and fell

... (http://rockandice.com/articles/how-to-climb/article/1092-rope-choppedbycarabiner)

d. Suddenly, the rope cut and he fell down the well.

(http://www.englishforfun.bravehost.com/wishingwell.htm)

${ }^{8}$ The case is not limited to names of cities, countries, and similar entities, and the kinds of polysemy we have considered so far, though these are particularly illustrative. Many proper nouns enter into different patterns of regular polysemies (like the author-for-works-of-author pattern, or location-for-event pattern this is a new Vietnam). Moreover, proper nouns of persons can be said to be able to refer to at least two different entities: the body and the person, as exemplified by the two different readings of John is very flexible, depending on the two different aspects associated to the proper name John (John, as a person, is very flexible; John, as a body, is very flexible). Concerning the adjective flexible, I would like to tell a story similar to that told about verbs: the specific senses it has in different utterances of John is flexible are related to the rich meaning provided by the noun.
} 
However, the picture that emerges from what we have seen above seems to jeopardize the interesting dichotomy between some nominals and the rest of words, and, what is worse, it leads us to an apparent cul-de-sac. Remember that three kinds of polysemies have been distinguished: inherent, merely regular, and metaphor-based, irregular polysemies. It has been held that the first two kinds suggest an overspecification approach, while the third kind favors an underspecification account. The problem is that both regular and irregular, metaphor-based, polysemy affect kind-terms, as shown by (15a-m).

(15a) Open your mouth.

(15b) He has a beautiful mouth.

(15c) You cannot live without a mouth.

(15d) Put that into your mouth.

(15e) I have a pain not in my teeth, but in my mouth.

(15f) Wonderful words came out of her mouth.

(15g) Jim has such a big mouth: you cannot trust him.

(15h) They call him The Mouth of Sauron: he is Sauron's messenger.

(15i) They went as far as to give the family dog mouth to mouth.

(15j) Storytelling and oral tradition are forms of word of mouth that play important roles in folklore.

(15k) The expedition reached the mouth of the Amazon.

(15l) She is always putting words in my mouth.

(15m) In the evenings a large flock of swifts circle the mouth of the cave... ${ }^{9}$

(15a-f) are (12a-f) above, and arguably exemplify a polysemy of aspects. (15g-m) are metaphorical, but conventionalized, uses of mouth. Each metaphorical sense relates to, but does not denote, one of the aspects highlighted in (15a-f). Rather, the metaphorical senses look like elaborations of the original (15a-f) aspects.

According to what has been laid out above, we should acknowledge: (a) that mouth has a rich meaning that includes all different aspects/senses highlighted in (15a-f), and (b) that mouth has a thin meaning that applies to all its different metaphorical (15g-m) and non-metaphorical senses. The tension is self-evident and compromises the neat conclusions we suggested in the previous sections, where we established that, while regular polysemy requires a rich meanings account, metaphor-based polysemy calls for

\footnotetext{
${ }^{9}$ For more examples of the polysemy of mouth and its cognates in different languages, see Nissen, 2011.
} 
an underspecification approach. Such conclusions need to be nuanced, but it is not obvious in which way.

One possibility is to revise what has been said above concerning metaphor-based polysemy, and give more credibility to the idea that all senses of a polyseme are stored in one single, "super-rich”, representation. However, this approach is not appealing. Apart from the reasons considered above against the general case, there are some more specific reasons to reject that all senses of a noun can be part of a single representation. Examples (15g-m) show that different metaphorical chains relate to different aspects of the metonymically generated meaning of mouth. Thus, MOUTH (OF A RIVER) relates to the aperture sense/aspect of MOUTH (OF A PERSON), while (BIG)MOUTH relates to its speech organ sense. Now, suppose that (BIG)MOUTH primes MOUTH (OF A PERSON), just as MOUTH (OF A RIVER) does (MacGregor et al., 2015). The question is whether (BIG)MOUTH and MOUTH (OF A RIVER) would also prime each other. The super-rich hypothesis requires that they should, because by hypothesis, they belong to the same representation.

To my knowledge, there is no study that could illuminate this precise question. However, we may assume that (big)mouth and mouth (of a river) express "distant senses" (i.e., they are not closely related by metonymy or similarity), as (shredded) paper and (liberal) paper do. Now, what we know about distant senses such as the ones expressed by this pair is that they behave more like the meanings of homonymous terms (there are clear dominance effects and there is no co-priming, but competition, between them). So, it seems reasonable to think that distant senses are stored in different representations (Klein and Murphy, 2001, Foraker and Murphy, 2012, Rabagliati and Snedekker, 2013). If this is also the case with respect to (BIG)MOUTH and MOUTH (OF A RIVER), then the idea that all senses of mouth may belong to a single representation has to be wrong.

Co-priming, as "being close to," is not a transitive relation. If there is co-priming between $\mathrm{A}$ and $\mathrm{B}$ and between $\mathrm{B}$ and $\mathrm{C}$, then it does not need to be the case that there is co-priming between $\mathrm{A}$ and $\mathrm{C}$. This suggests that there are senses that are more central than others. A plausible case is that the most central sense of, e.g., mouth is actually not a sense but a collection of senses or aspects. That is, the central meaning of mouth is the complex, rich, meaning that we can label MOUTH (OF A PERSON). The different aspects of this complex are related to different metaphorical but conventionalized meanings of mouth, such that they are able to activate these meanings and be activated by them (an activation, which in turn, activates the whole complex). A possibility is that this coactivation of aspects and metaphorical meanings/senses of nouns takes place via feature activation. That is, the features that compound the APERTURE aspect in MOUTH (OF A PERSON), in particular, those shared by the sense MOUTH (OF A RIVER), are responsible for the activation that goes in both directions; some of the features that compound the SPEECH ORGAN sense of mouth are responsible for the co-activation of its meaning and of the senses expressed by bigmouth and Mouth of Sauron, etc. 
The picture that emerges, then, is one where the meaning formed by the different aspects of a noun play the role that underspecific representations play in metaphorbased polysemies generally: i.e. they provide features that channel the activation towards metaphorical senses and back. In sum, it can still be maintained that the meaning of some nouns is formed by a series of aspects constituting a single representation, and thus, that these nouns have a differentially rich meaning.

\section{Conclusion}

There has been somewhat little research on the meaning of lexical words, and, likewise, little systematic research on polysemy. There has even be less work on relating both these topics, even though it is obvious that they must be related. Polysemy is starting to attract some attention in psycholinguistics, but the results we have to date still require a lot of discussion and clarification, as well as a better integration with theoretical models. In this paper, I scratched the surface of what could be an integrative model of polysemy, and of how it could affect our models of word meaning. I am aware that there are some loose ends in the picture I have tried to put forward. However, I hope that I was able to convince the reader that the overall approach makes sense and is worth pursuing further. The approach has it that there is a difference at the level of meaning between kind terms (and some proper nouns) and the rest of words. The main argument supporting this distinction is that kind terms enter into patterns of polysemy that call for a rich meaning approach, while verbs, adjectives, adverbs, and prepositions, while massively polysemous, are affected only by metaphor-based polysemy, which suggests a thin, underspecification approach. Additional support for this view comes from reflections on the nature of kind concepts (vs. the rest), as well as by looking at how the interaction between the meanings of nouns and the meanings of verbs explains some semantic observations. In this regard, I suggest that what meaning or sense a verb or an adjective expresses in a given context depends on the information stored in the meaning of its argument and on what part or aspect of that information is selected.

\section{Acknowledgments}

This work benefited from comments from Andreas Brocher, Ingrid Lossius Falkum, Lotte Hogeweg, Marina Ortega, Tim Pritchard, Alexandra Spalek, and an anomymous reviewer. Research for this work was funded by Projects IT769-13 (Basque Government) and FFI2014-52196-P, of the Spanish Ministry of Economy and Competitiveness (MINECO).

\section{References}

Apresjan, J. D. (1974). Regular polysemy. Linguistics, 14(2), 5-32.

Arapinis, A \& Vieu, L.(2015) A plea for complex categories in ontologies. Applied Ontology, 10: 285-296.

Asher, N. (2011). Lexical Meaning in Context. Cambridge: Cambridge University Press. Asher, N. (2015) Types, meanings and coercions in lexical semantics, Lingua, 157: 6682. 
Azuma, T., \& van Orden, G. C. (1997). Why safe is better than fast: The relatedness of a word's meanings affects lexical decision times. Journal of Memory and Language, 36, 484-504.

Bierwisch, M., \& Schreuder, R. (1992). From concepts to lexical items. Cognition 42: 23-60.

Brocher, A., Foraker, S. \& Koenig, J-P. (2016) Processing of irregular polysemes in sentence reading. Journal of Experimental Psychology: Learning, Memory, and Cognition, 42(11): 1798-181.

Brugman, C. (1988). The Story of over: Polysemy, Semantics, and the Structure of the Lexicon. New York: Garland.

Carey, S. (2009). The Origin of Concepts. New York: Oxford University Press.

Carston, R. (2002). Thoughts and Utterances: The Pragmatics of Explicit Communication. Oxford: Blackwell Publishers.

Carston, R. (2012). Word meaning and concept expressed. The Linguistic Review, 29: 607-623.

Chomsky, N. (2000). New Horizons in the Study of Language and Mind. Cambridge, England: Cambridge University Press.

Copestake, A., \& Briscoe, T. (1995). Semi-productive polysemy and sense extension. Journal of Semantics, 12: 15-67.

Cruse, D. A. (2004). Meaning in Language: An Introduction to Semantics and Pragmatics. Oxford: Oxford University Press.

Dölling, J. (forth) Systematic Polysemy. In Matthewson, L., Meier C., Rullmann, H. \& Zimmermann, T.E. (eds.) The Blackwell Companion to Semantics.

Dowty, D. (1979). Word Meaning and Montague Grammar. Dordretcht: Reidel.

Elman, J. (2009). On the Meaning of Words and Dinosaur Bones: Lexical Knowledge Without a Lexicon. Cognitive Science 33: 547-582.

Evans, V. (2009). How Words Mean: Lexical Concepts, Cognitive Models and Meaning Construction. Oxford: Oxford University Press.

Falkum, I. L. (2010) Systematic polysemy and the count-mass distinction. UCL Working Papers in Linguistics 22: 16-40.

Falkum, I. L. (2011). The Semantics and Pragmatics of Polysemy: A RelevanceTheoretic Account. (PhD), University College London.

Falkum, I.L. (2015) The how and why of polysemy: A pragmatic account. Lingua, 157: 83-99.

Falkum, I.L. (forth.) The lexical pragmatics of count-mass polysemy, Semantics and Pragmatics.

Falkum, I.L. \& Vicente, A. (2015) Polysemy: Current perspectives and approaches. Lingua, 157: 1-16.

Fennell C. \& Waxman, S. R. (2010) "What paradox? Referential cues allow for infant use of phonetic detail in word learning”, Child Development, 81: 1376-1383.

Foraker, S. \& Murphy, G.L. (2012). Polysemy in sentence comprehension: Effects of meaning dominance. Journal of Memory and Language, 67: 407-425.

Frisson, S. (2009). Semantic Underspecification in Language Processing, Language and Linguistics Compass, 3: 111-127. 
Frisson, S. (2015). About Bound and Scary Books: The Processing Of Book Polysemies, Lingua 157: 17-35.

Frisson, S. and Frazier, L. (2005). Carving up word meaning: Portioning and grinding. Journal of Memory and Language 53: 277-291.

Hank, P. (2013). Lexical Analysis: Norms and Exploitations. Cambridge, MA: MIT Press.

Hogeweg, L. (2012). Rich Lexical representations and conflicting features, International Review of Pragmatics 4: 209-231.

Jackendoff, R. (1992). Languages of the mind. Cambridge, MA: MIT Press.

Katz, J. J. (1972). Semantic Theory. New York: Harper \& Row.

Kilgarriff, A. (1992). Polysemy. PhD Thesis, University of Sussex.

Klein, D. E., \& Murphy, G. L. (2001). The representation of polysemous words. Journal of Memory and Language, 45: 259-282.

Klepousniotou, E., \& Baum, S. R. (2007). Disambiguating the ambiguity advantage effect in word recognition: An advantage for polysemous but not homonymous words. Journal of Neurolinguistics, 20: 1-24.

Klepousniotou, E., Titone, D., \& Romero, C. (2008). Making sense of word senses: the comprehension of polysemy depends on sense overlap. Journal of Experimental Psychology: Learning, Memory, and Cognition, 34: 1534-1543.

Klepousniotou, E., Pike, G.B., Steinhauer, K., Gracco, V. (2012). Not all ambiguous words are created equal: An EEG investigation of homonymy and polysemy. Brain and Language, 123, 11-21.

Knobe, J., Prasada, S., \& Newman, G. E. (2013). Dual character concepts and the normative dimension of conceptual representation. Cognition, 127: 242-257.

Lakoff, G. (1987). Women, Fire, and Dangerous Things: What Categories Reveal about the Mind. Chicago, Illinois: The University of Chicago Press.

Langacker, R. W. (1984). Active zones. Proceedings of the annual meeting of the Berkeley Linguistics Society, 10: 172-188.

Li, L., \& Slevc, R.L. (2016). Of Papers and Pens: Polysemes and Homophones in Lexical (mis)Selection. Cognitive Science, DOI: 10.1111/cogs.12402

MacGregor, L.J., Bouwsema, J., \& Klepousniotou, E. (2015) Sustained meaning activation for polysemous but not homonymous words: Evidence from EEG. Neuropsychologia, 68: 126-138.

Machery, E. and Seppälä, S. (2011). Against hybrid theories of concepts, Anthropology and Philosophy, 10: 99-126.

Millikan, R. (2000). On Clear and Confused Ideas. Cambridge, MA: Cambridge University Press.

Moravcsik, J. M. (1975). Aitia as Generative Factor in Aristotle's Philosophy, Dialogue, 14:622-36.

Nissen, Uwe Kjær. (2011). Contrasting body parts. Metaphors and metonymies in Danish, English, and Spanish. In Maalej, Z. \& Yu Ning. Embodiment via Body Parts. Studies from various languages and cultures. Amsterdam, New York : John Benjamins Publishing Company, 71-92. 
Paradis, C. (2004). Where does metonymy stop? Senses, facets, and active zones. Metaphor and Symbol, 19: 245-264.

Pietroski, P. (forth.) Semantic Internalism. In J. McGilvray, ed The Cambridge Companion to Chomsky. Cambridge University Press.

Pritchard, T. (2017) Knowing the Meaning of a Word: Shared Psychological States and the Determination of Extensions, Mind and Language, 32: 101-121.

Pustejovsky, J. (1995). The Generative Lexicon. Cambridge, Massachusetts: The MIT Press.

Pustejovsky, J. (2005). A survey of dot objects. Author's Weblog.

Rabagliati, H. \& Snedeker, J. (2013). The truth about chickens and bats: Ambiguity avoidance distinguishes types of polysemy. Psychological Science, 24, 13541360.

Rappaport Hovav, M. (2014). Lexical content and context: The causative alternation in English revisited. Lingua, 141, 8-29.

Rayo, A. (2013). A Plea for Semantic Localism, Nous, 47: 647-79.

Recanati, F. (2004). Literal meaning. Cambridge: Cambridge University Press.

Spalek, A. (2015). Spanish Change of State Verbs in Composition with Atypical Theme Arguments: Clarifying the Meaning Shifts, Lingua, 157: 36-53.

Sperber, D., \& Wilson, D. (1986/1995). Relevance: Communication and Cognition. Oxford: Blackwell.

Sperber, D., \& Wilson, D. (1998). The mapping between the mental and the public lexicon. In P. Carruthers \& J. Boucher (eds.), Language and Thought: Interdisciplinary Themes, Cambridge: Cambridge University Press, 184-200.

Srinivasan, M. \&Rabagliati, H. (2015) How concepts and conventions structure the lexicon: Cross-linguistic evidence from polysemy. Lingua, 157: 124-152.

Travis, C. (2008). Occasion-Sensitivity: Selected Essays. Oxford: Oxford University Press.

Vicente, A. (2012). On Travis cases. Linguistics and Philosophy, 35, 3-19.

Vicente, A. (2015). The green leaves and the expert: Polysemy and truth-conditional variability. Lingua, 157: 54-65.

Vicente, A., \& Martínez-Manrique, F. (2016). The big concepts papers: a defence of hybridism. British Journal for the Philosophy of Science, 67: 59-88.

Yalcin, S. (2014) Semantics and Metasemantics in the Context of Generative Grammar. In A. Burgess and B. Sherman, eds. New Essays in Metasemantics. New York: Oxford University Press.

Zwarts, J. (2004). Competition between Word Meanings: The Polysemy of (A)Round. In Meier, C. and Weisgerber, M. (eds.), Proceedings of SuB8. Konstanz, University of Konstanz Linguistics Working Papers.

Zwicky, A., \& Sadock, J. (1975). Ambiguity tests and how to fail them. In J. P. Kimball (Ed.), Syntax and Semantics, Volume 4 (pp. 1-36). New York: Academic Press. 